\title{
Também foi assim que as coisas se passaram
}

MARTA LANÇA

Marta Lança é doutoranda em Estudos Artísticos na FCSH, UNL e pesquisa a ideia de «sul» na programação cultural. Formou-se em Estudos Portugueses, com pós-graduação em Literatura Comparada e Edição de Texto. Tem trabalhado como jornalista, tradutora, editora e produtora. Desde 2004 dedica-se a questões culturais entre África, Europa e Brasil. Escreveu para várias publicações sobre cultura e lusofonia. Criou o portal BUALA, de que é editora. Foi editora da Rede Angola. Fez pesquisa e produção para documentários. Traduziu Crítica da Razão Negra, de Achille Mbembe (Antígona).

This paper will address the issue of transmission of memory and its relationship with the Portuguese recent history, from the performative lecture of Joana Craveiro Um Museu Vivo de Memórias Pequenas e Esquecidas [A Living Museum of Small and Forgotten Memories] (2014). We tried to articulate the concepts of cultural memory with the small memory (which makes us unique in contrast with the large and widespread memory), from a narration of the post-memory generation, following the creative process of this work. In line with the artistic productions of Teatro do Vestido (the theatre company owned by Joana Craveiro), which since 2001 has worked exclusively with original texts of autobiographical nature, A Living Museum is built on several starting points, articulates various strands of a complex history and allows filling the blanks in the conventional narrative about Portuguese recent history. The macrostructure follows the chronological order - the dictatorship, the re-enactment of the day of the revolution, and finally, after the (celebratory) popular dinner, comes the subsequent revolutionary process (PREC).The material comes from a repository, and according to the artistic perspective of Craveiro's and her selection criteria, is turned into an interpretative monologue that calls many other voices through an inclusive construction: "The Museum is mine, but it's also of the people who had never had a voice and whose voice I wanted to hear."

POST-MEMORY / POLITICS / TRANSMISSION / HISTORY / REVOLUTION / LECTURE PERFORMANCE

Há um acordo secreto entre as gerações passadas e a geração atual. WALTER BENJAMIN

Passaram 40 anos e é altura de questionar quem é que em Portugal têm sido os donos da memória.

JOANA CRAVEIRO

Memória cultural e memória coletiva, às quais acresce a pequena memória, a pós-memória e a transmissão da memória, são alguns 
dos conceitos que bailam na peça Um Museu Vivo de Memórias Pequenas e Esquecidas. Como se tem transmitido a ditadura, o 25 de Abril e o PREC? O que nos ficou dos traumas de um longo período de isolamento e das aceleradas agitações políticas posteriores? A criação de Joana Craveiro, um museu em construção composto por vários arquivos pessoais, conduz-nos numa reflexão e num aceso e alargado debate à memória desses tempos a partir do ponto de vista da geração que não viveu o 25 de Abril mas que é filha do 25 de Abril. Esta transmissão, incorporando o passado na defesa do não esquecimento e de uma comunidade por vir, a sua potência de relação temporal - encontro entre gerações -, a predisposição para compreender o «escuro do presente» que agencia a sua transformação, traduz o olhar contemporâneo, nos termos de Agamben (2009).

O passado oficial (também ele variável no tempo como resposta à atualidade) tem sido fixado, em termos institucionais, num sentido de unidade e paz, mesmo tratando-se da mais atroz violência que pode até implicar quem o celebra (Hite, 2012). Não é demais lembrar quanto da nossa memória cultural se deve às políticas comemorativas e às suas retóricas de legitimação, à cultura visual, a determinados artefactos eleitos como símbolos e a narrativas que, não raramente, veiculam uma memória acrítica. Assim, Joana Craveiro empreende este «trabalho de reconstituição contra a usura do tempo e das ideologias vigentes» (a história oficial e suas versões simplificadas; tal como se pode ler no sítio do Teatro do Vestido: http://teatrodovestido.org/blog/). Na linha das criações deste coletivo teatral que, desde 2001, trabalha exclusivamente textos originais de pendor autobiográfico, são assim desfiadas as pontas de uma história complexa, num monólogo interpretativo que convoca outras vozes além da autora, as pessoas que ela quis ouvir: resistentes, presos políticos, retornados, historiadores, cineastas, vizinhos, colegas da escola, amigos dos pais, membros da família.

\section{A PEQUENA MEMÓRIA DE UMA FOTOGRAFIA COM OS ALPES SUÍÇOS}

Com este sentido inclusivo, e contrapondo histórias mais pessoais à narrativa fixada pelos mecanismos de legitimação, a autora reclama-se do conceito de «pequenas memórias sobre pequenas coisas» de Christian Boltanski (2009). Para o artista francês, a nossa singularidade reside na pequena memória, constituída por 


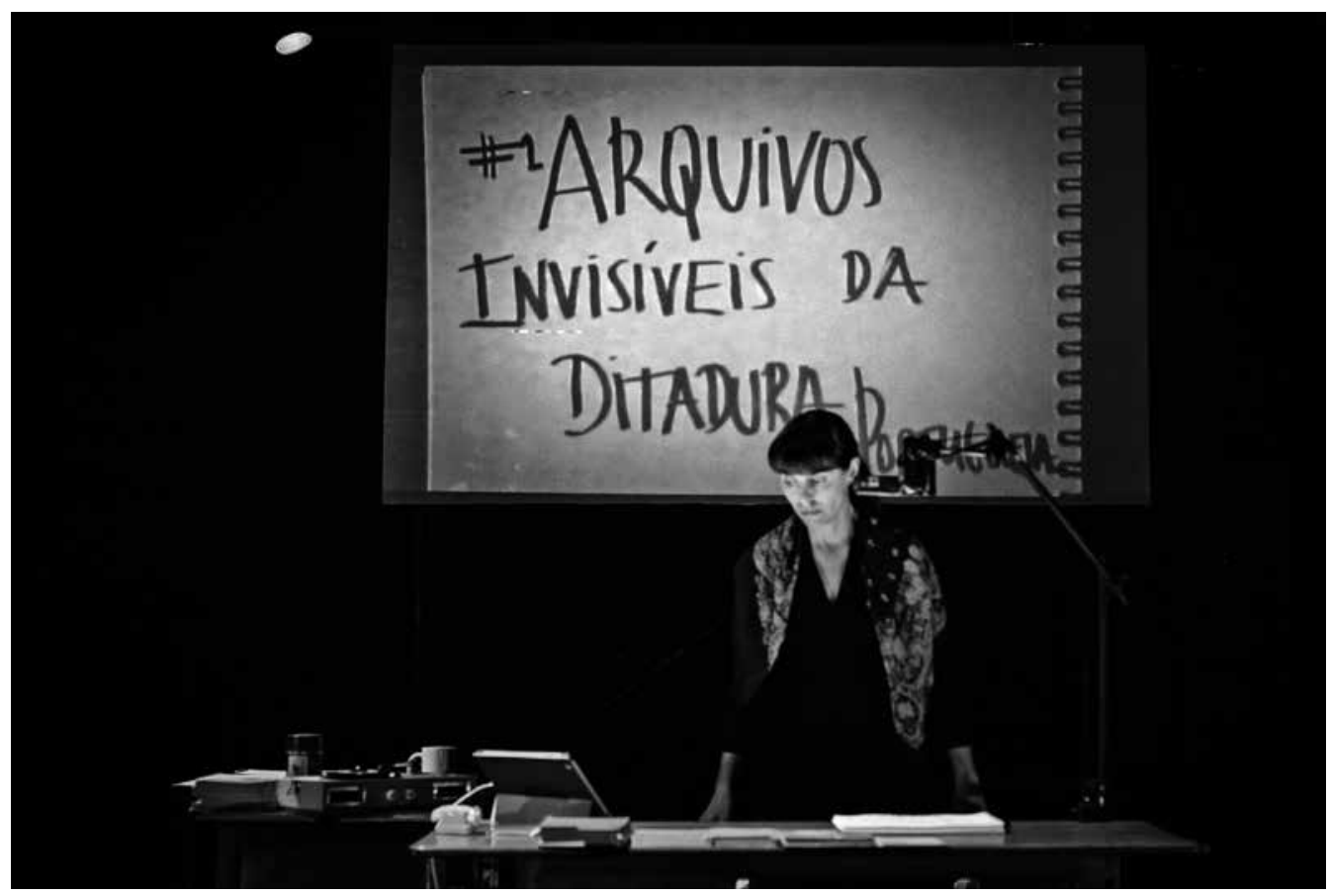

UM MUSEU VIVO DE MEMÓRIAS PEQUENAS E ESQUECIDAS, DE JOANA CRAVEIRO, TEATRO DO VESTIDO, 2015 (JOANA CRAVEIRO), [F] JOÃO TUNA pequenas coisas sem valor, banalidades, menos presa aos factos do que às emoções e vida quotidiana. Em contraste com a grande memória, amplamente difundida, a pequena memória seria assim frágil e dissipada pela morte, com a qual a pessoa passa de sujeito a objeto, retendo-se apenas a roupa, um nome, uma imagem. Nesta abordagem, Boltanski evoca a resistência individual em relação às massas através dos «pequenos saberes» que nos definem enquanto indivíduos (2009).

A memória pequena e esquecida permite ainda preencher os espaços em branco da narrativa convencional: as omissões, revisões, rasuras, as outras versões que podemos aprender. $\mathrm{Na}$ peça, a ironia vai-se apoderando das narrativas oficiais que ainda pesam sobre estes períodos cruciais do século Xx português - a ditadura, a revolução - para encontrar eco nas «explicações simplistas sobre como chegámos até aqui». Urdindo o já referido diálogo de tempos, a longa duração da ditadura e a excecionalidade do PREC são, por exemplo, relacionadas com o discurso da crise e com o anticomunismo primário de hoje; o 11 de Março e as nacionalizações reverberam ainda na atual desconfiança generalizada em relação aos políticos. 
O que permanece então do passado são narrativas, vestígios fluidos e culturalmente mediatizados, que temos de decifrar. Ao fazer a reconstituição da história dos pais e do país (memória pessoal e coletiva), nesta peça o passado assemelha-se a um crime a ser investigado (para entendermos o absurdo do presente?). É que a memória diz sempre respeito ao presente (Halbwachs, 1992), devendo resposta a interesses e anseios da atualidade, de acordo com os quais se sacraliza ou se omite o passado. «Quis compreender o presente do país sobre mais qualquer coisa do que o passado recente. $\mathrm{O}$ que restava da mentalidade desses tempos na minha família» (Nadais, 2014a), diz Joana Craveiro, em entrevista a Inês Nadais. O seu trabalho situa-se no terreno, inevitavelmente acidentado, do subjetivo e, nesse sentido, está lá a possibilidade de incluir o que podia ter acontecido, funcionando esta sobreposição de tempos como uma alternativa. $O$ que as pessoas se lembram não corresponde à «verdade» histórica, «a pessoa que eu era nesse tempo já não sou eu» ou a autoironia de um «nós éramos assim». A memória funciona, portanto, como uma construção quotidiana que combina sensações, realidades e pontos de vista: é um policial difícil de desvendar.

\section{ANTES, DURANTE E DEPOIS}

As apresentações integrais têm quatro horas que passam num ápice, com jantar popular pelo meio para o qual o público se deslocou como se estivéssemos no «calor da revolução», empunhando megafones e bandeiras. Vários atos compõem os materiais de Um Museu Vivo, inicialmente apresentados em sessões autónomas: «Atos de Resistência», «Arquivos Invisíveis da Ditadura Portuguesa», «Português Entrecortado» e «Quando É Que a Revolução Acabou?». A coleção deste museu inclui as «construções nacionais» sobre as quais se funda o Estado Novo e as formas de resistência que as acompanham (Atos de Resistência), por exemplo no ato de resistência individual simbolizado por comprar um livro proibido que a atriz descreve em torno da figura cúmplice do livreiro da Ulmeiro. Faz também uma breve abordagem à Guerra Colonial e aos dias turbulentos da descolonização (Espantados de Regressar), já abordados também no espetáculo Retornos, Exílios e Alguns Que Ficaram 
(apresentado no Festival Todos, em 2014) e na performance Páginas de Um Império Perdido \#1: Alguns que retornaram e outros que não quiseram (integrado no projeto Retornar - Traços de Memória, Padrão dos Descobrimentos, novembro de 2015).

No ato «Quando É Que a Revolução Acabou?», questionam-se as terminologias, investigadas as possíveis narrativas ou balizas temporais e as mentalidades dissonantes acerca do momento final da revolução. Este ponto de partida trouxe outras questões: «de que revolução estamos realmente a falar?», «é uma revolução ou são mais?» e «o que é que as pessoas sentiram com o fim da revolução?».

\section{O OLHAR EXTERIOR MAS TAMBÉM IMPLICADO DA PÓS-MEMÓRIA}

Tem-se relacionado a pós-memória com os descendentes de sobreviventes de eventos dolorosos que, embora não tenham testemunhado esses eventos em primeira mão, herdam a experiência traumática de quem a vivenciou, através de uma narrativa familiar (Hirsch, 1997). Reforçando a ideia de que os efeitos do passado continuam no presente, e que não se quer pôr termo a determinado assunto, esta ligação é mediada por investimento imaginativo, projeção e criação. Crescer com memórias herdadas, mais ou menos esmagadoras, faz que as nossas próprias histórias de vida se situem na sombra de um mistério maior. Ainda que indiretamente, esses fragmentos de eventos que precedem o nosso nascimento ou a nossa consciência tornam-se um desafio para a compreensão.

Em Um Museu Vivo, interessa-nos menos a especificidade do trauma do que a relação com a memória dos ascendentes e a sua repercussão no presente. A condição de «pós» advém mais da tentativa de reconstituição subjetiva, na medida do (im)possível, de como as coisas «realmente se passaram». Escreve Joana Craveiro:

\footnotetext{
A nossa memória é, portanto, pós e é nessa condição de um «outro olhar» que temos vindo a construir as palestras performativas que fazem parte deste museu, como uma lição de história que não se aprende em nenhuma disciplina que conheçamos - e talvez por isso mesmo estejamos a construir este espetáculo: por nunca o termos podido aprender mesmo quando pedimos que nos ensinassem, que nos contassem como as coisas se tinham «realmente» passado.

http://teatrodovestido.org/blog/?p=5334
} 
A geração pós-memória, mais do que tendo vivido experiências em conjunto, partilha percepções e memórias, com maior ou menor grau de identificação. A geração dos «filhos de Abril» está em condição privilegiada de pensar as memórias indiretas, ou de partilhar as perceções destas memórias que, a par das estruturas sociais e culturais, nos definem como geração. Este «outro olhar» não toma partido declaradamente, nem tem a visão turvada pela autoridade do «eu estive lá e sei», ainda que o grau de afetividade por estes assuntos seja proporcional ao tipo de narrativa ideologizante que lhe foi transmitida. Pelo contrário, $\mathrm{o}$ distanciamento potencia a ironia, o questionamento, a denúncia de algumas promessas e a observação crítica das metamorfoses da geração anterior, protagonista dos acontecimentos. Escreve Joana Craveiro: «Assumo uma voz subjetiva, que é a minha e também a da geração da pós-memória, que tem dúvidas, que tem perguntas, que tem ironia» (Nadais, 2014b). O museu pessoal de uma criadora nascida no pós-25 de Abril potencia um elevado grau de identificação em termos de dúvidas, referências, percepções - também foi assim que as coisas se passaram -, tanto para os contemporâneos da revolução como para os «vindouros» da democracia portuguesa.

\section{MATERIAIS DE DIVERSAS NATUREZAS}

Cada palestra tem a sua caixa de adereços a partir dos quais Craveiro desenvolve as suas histórias. Se abrirmos uma delas podemos encontrar: souvenirs chineses; um telefone; soldados em miniatura para a cena da Guerra Colonial; cravos murchos; Memórias de Um Operário, de José da Silva; Massacres na Guerra Colonial, ed. Ulmeiro; Pais de Abril, Filhos de Novembro, de Tiago Matos Silva; a visita de Simone de Beauvoir a Portugal e os seus comentários; as histórias das cooperativas culturais; o livreiro José Ribeiro, que conseguia passar livros proibidos, e a história de quando foi preso pela PIDE; o Guide du Portugal, de Franz Villier; uma lista de livros proibidos; Salazar, a Arte de Saber Durar, de Fernando Rosas; Salazar, de Hugh Kay; vários livros sobre a PIDE e testemunhos de polícias e de presos políticos; histórias de tortura; a história da presa política Aurora Rodrigues, e o livro com o seu testemunho Gente Comum; a figura do militante incómodo em Francisco Martins Rodrigues; o panfleto «Se Fores Preso, 
UM MUSEU VIVO DE MEMÓRIAS PEQUENAS E ESQUECIDAS, DE JOANA CRAVEIRO, TEATRO DO VESTIDO, 2015 (JOANA CRAVEIRO), [F] JOÃO TUNA

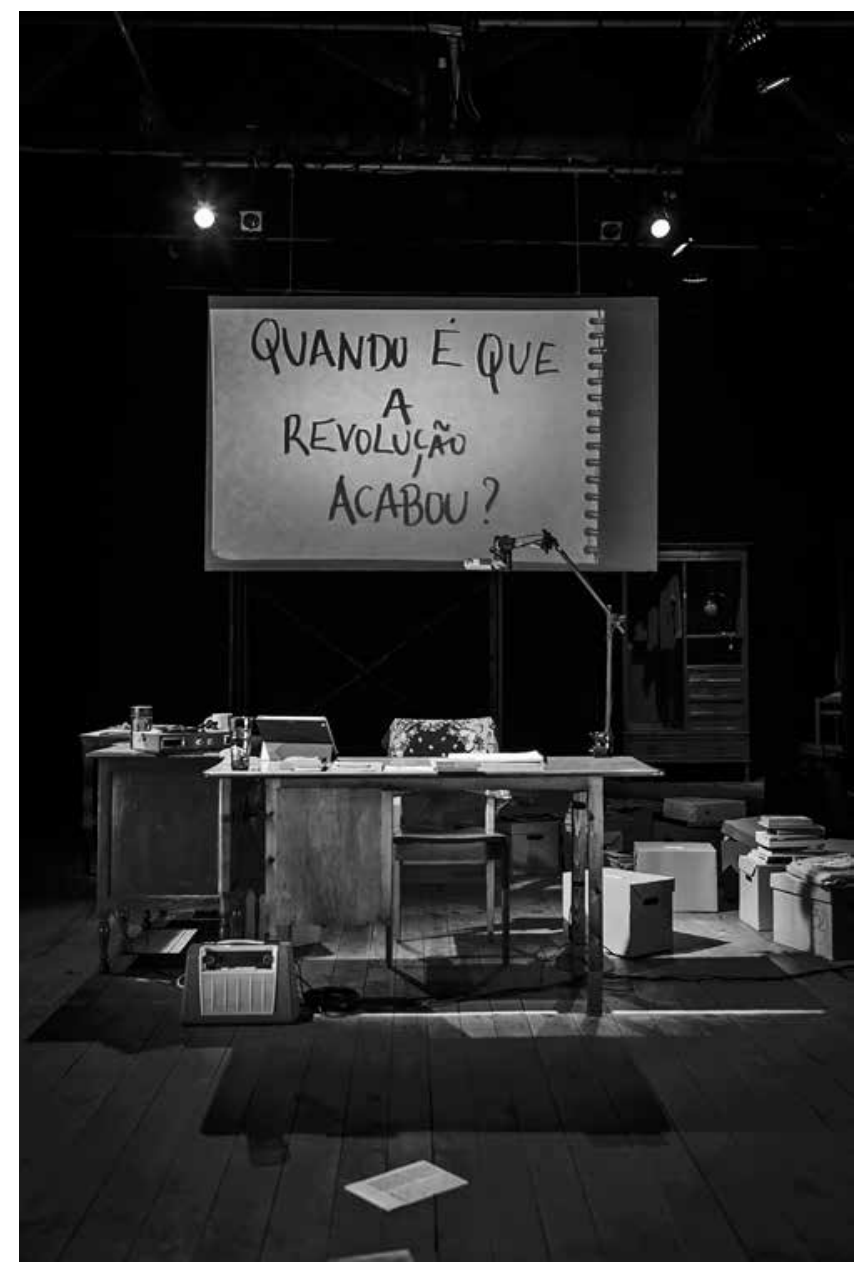

Camarada»; a história de Ribeiro Santos, estudante assassinado pela PIDE, e as manifestações em sua homenagem assim como o simbólico funeral; Os Rapazes dos Tanques, de Adelino Gomes e Alfredo Cunha; Portugal, the Impossible Revolution?, de Phil Mailer; O Fascismo nunca Existiu, de Eduardo Lourenço; os livros e a figura de Augusto Abelaira; State Repression and the Struggles for Memory, de Elizabeth Jelin e Peter Robinson; relatos das comissões de moradores; histórias do processo SAAL; relato da rádio do dia 25 de Abril; as canções no Rádio Clube Português; a coleção «Política do Espírito», de António Ferro; livros infantis como Contos Populares Chineses e Rebentos de Arroz; o Manual da Mocidade Portuguesa; a comissão do Livro Negro do Fascismo (dez volumes), criada em 1978 para averiguar os crimes do fascismo, que Cavaco Silva desmantela em 1991; documentos sobre a visita de 
Marcelo Caetano a Londres, onde foi muito apupado; histórias da descolonização e de retornados com testemunhos de famílias em cassetes e o diário de uma família em Angola desde 1948; uma saia de casamento de 1978; a caixa que o pai da atriz ia doar ao Centro de Documentação do 25 de Abril; fotografias de um homem na Guerra Colonial; uma intimação da PIDE, ao cuidado de Laurentina da Conceição Silva, para prestar declarações na «repartição» da rua do Heroísmo às 15 horas do dia 25 de abril de 1946; a história da placa da antiga sede da PIDE e o destino naquele edifício; um livro proibido de Pamela Moore, Chocolates ao Pequeno-Almoço, que, na verdade, não era sobre culinária mas sobre o despertar sexual de uma mulher; um disco do Movimento Nacional Feminino que os soldados portugueses ouviram em Angola e Moçambique no Natal de 1961; os panfletos em que o MRPP deseja «longa vida, muito longa vida ao camarada Mao Tsé-Tung»; o 1,49\% de Otelo nas presidenciais de 1980; uma fotografia da atriz na escola primária no tempo em que Portugal queria ser como a Suíça; e viria a acrescentar os jornais de 11 de março de 2015, cujas capas saíram todas a vermelho, numa campanha da Vodafone. Tanta diversidade organiza-se no fio condutor dramatúrgico dos «cadernos do arquivista», que vão sendo folheados ao longo da peça como uma espécie de guião. Uma câmara filma em direto os livros, objetos, fotografias, dispostos com sequências bem marcadas, isto é, na forma de mostrar, de sobrepor e de relatar os materiais, são-nos sugestionadas «memórias visuais». Inserido numa certa tendência internacional, também da arte contemporânea, que trabalha com a História e o arquivo, relacionamos este tipo de teatro documental com as encenações de Lola Arias sobre a Argentina e o Chile, países com passados recentes de inquestionável violência. Recorrendo igualmente à filmagem direta dos objetos de cena, em Mi vida después e em El año en que nací (no Próximo Futuro 2012), jovens argentinos e chilenos, respetivamente, reconstroem a juventude dos seus pais nos anos 70 sob a ditadura de Pinochet a partir de fotografias, cartas, cassetes, roupa usada, recordações rasuradas. Quem eram os meus pais quando eu nasci?, como era o Chile dessa época?, quantas versões existem sobre o que se passou quando era tão pequenino que não tenho memórias? foram algumas perguntas na base do espetáculo.

$\mathrm{O}$ «outro olhar» reclamado por esta geração tem curiosidade. Reconhecemos nestes trabalhos um movimento de dentro para 
fora, do privado para o público, da família para a sociedade. «Quis investigar dentro da minha própria família porque havia muitas coisas que até hoje não sabia e porque a transmissão da memória no contexto familiar é determinante neste processo de assimilação do passado», explica Craveiro (Nadais, 2014b).

MEMÓRIA, UM CAMPO DE ESTUDOS

Os estudos da memória foram impulsionados pelos estudos sobre o Holocausto, enquanto acontecimento esmagador e de exceção. A sua capacidade de distorção e de violência fez questionar o potencial e os limites da memória. Outro eixo central é o modo de incorporar a memória a partir de artefactos culturais. Marita Sturken (que tem trabalhado a identidade nacional, a cultura visual e popular, o consumismo e os efeitos culturais da tecnologia) refere que os trabalhos mais interessantes sobre a memória provêm de inovações recentes na historiografia que deslocaram o interesse dos objetos culturais para as práticas de cultura, incidindo na interpretação das formas e atividades culturais. Esta valorização das práticas ajudou a definir a memória «como um processo dinâmico que resulta de práticas de memorialização, ritual, criação de santuários, debates e lutas pelos significados da memória que emergem da construção das instituições da memória» (Sturken, 2008: 74). O trabalho de Craveiro atravessa várias ondas da memória: devolve a dimensão simbólica aos ícones rasurados, como o estudante assassinado, os presos políticos, a descrição na primeira pessoa de algumas torturas da PIDE por Aurora Rodrigues; retira à invisibilidade certas figuras, como a de Vasco Gonçalves; faz-nos experienciar o momento radiofónico do 25 de Abril, a azáfama da comissão de moradores numa ida à Margem Sul, ajuizar uma certa elite que foi maoísta ou comunista mais por voluntarismo, a vontade de abraçar ideologias que a prática da vida se encarrega de contradizer. Percebemos a importância de não só nomear como, pela recriação e narração de Joana Craveiro, formarem-se personagens na nossa cabeça: pessoas que viveram as circunstâncias históricas, arriscaram e sofreram.

\section{A VERTIGEM DO ARQUIVO}

O crescente interesse da arte contemporânea pela memória (na tentativa de ordená-la ou de reconfigurá-la) procura no arquivo 
e nos modos de organização mais o processo do que o fim em si. Nesse sentido, houve uma mudança de paradigma em relação às vanguardas modernistas, para as quais «o foco era o produto final de uma intervenção na memória» (Pitella, 2013). Desde os anos 60 que o processo de colecionar, inventariar, criar um arquivo passa a figurar no processo criativo. $\mathrm{O}$ archival impulse, diagnosticado por Hal Foster (2004:3-22), ajuda ao regresso da memória das imagens, para com elas, nas suas ligações rizomáticas, construir novas visões críticas.

Se um certo tipo de museu tem como função cristalizar as memórias, uma certa arte que utiliza o arquivo consegue dar a ver o invisível entre as imagens, no sentido de potenciar um olhar para as imagens mais limpo das suas narrativas históricas. Aproxima-se da ideia benjaminiana do anjo da História que olha para o passado a partir das suas cinzas, desfigurando e desmontando as narrativas que estruturam o passado (Richter, 200o). É como se se desejasse pôr alguma ordem naquilo que parece desordenado ou nos foi desapossado, fazendo uso de uma certa manipulação que ambiciona um novo pensamento. Ao expor-se ou destacar-se determinada forma, pondo em diálogo imagens e espaços diversos, produz-se uma nova ideia. Ou seja, materiais como fotografias e cartas são reenquadrados e recontextualizados, num jogo de ficção e de verdade, da visibilidade para a legibilidade (Didi-Huberman, 2010). Este processo permite experimentar possibilidades utópicas de um mundo transformado, incluindo o «podia ter sido» ou o «gostava que fosse», e de encontrar narrativas de resistência que ficaram invisibilizadas pela história dos vencedores. A peça $U m$ Museu Vivo também se situa neste apelo ao arquivo, tal como as anteriores criações do Teatro do Vestido se desenvolvem a partir desta estrutura: coleção de histórias, experiências, objetos, mapas, cartas, listas. Este trabalho específico insere-se no testemunho que incentiva a uma configuração original de materiais e sua releitura, comum a muitos arquivos artísticos. Esta prática arquivística coincide com o crescente interesse da arte sobre a história e o passado, e é assinada muitas vezes pela geração da «pós-memória», que, como referimos, resgata o passado da penumbra do arquivo. Confundindo os limites entre memória pública e privada, o arquivo deixa de ser um repositório de informação para contribuir para a memória coletiva, que não prescinde do posicionamento do artista perante o tema abordado. 
Contra a história das formas fechadas defende-se as formas abertas da cultura, sempre em atualização: o arquivo permanentemente em construção, instável e fluido aproximando-se de um arquivo digital, um «Museu Vivo». No final do espetáculo é-nos dado a ler um cartão: «Este museu vivo continua.» Segue-se uma conversa com o público-debate muito vívido no qual se manifestam opiniões, pontos de vista, experiências vividas, próximas ou conflituantes. A autora vai acrescentando ao seu museu elementos que provêm do confronto de ideias, tentativas de correção, novos dados. Porém, o trabalho de Joana Craveiro em Um Museu Vivo não é somente uma reorganização das pontas soltas de fragmentos da história recente portuguesa. Numa composição sincrética, desenha um modo alternativo de a transmitir, de ilustrar os paradoxos, de impossibilitar o consenso naquilo que implicou vidas. Posiciona-se pela liberdade, de perspetivas sim, mas também a liberdade de escolher a sua. Nestas várias abordagens à memória, reconhece-se a preocupação com o presente, a resistência da pequena memória que nos constitui e deve ser partilhada.

\section{REFERÊNCIAS BIBLIOGRÁFICAS}

AGAMBEN, Giorgio (2009), «What Is the Contemporary?», in What is an Apparatus? and Other Essays, Califórnia, Standford University Press.

BOLTANSKI, Christian (2009), La création contemporaine, Paris, Flammarion.

Didi-hubERMAN, Georges (2010), Remontages du temps subi. L'œil de l'Histoire, 2, Paris, Éditions de Minuit.

FOSTER, Hal (2004), «An Archival Impulse», October Magazine, n. ${ }^{\circ}$ 110, Ltd. and Massachusetts Institute of Technology, pp. 3-22.

HALBWACHs, Maurice (1992), On Collective Memory, Chicago, The University of Chicago Press.

HIRSCH, Marianne (1997), Family Frames: Photography, Narrative, and Postmemory, Cambridge, MA, Harvard University Press.

HITE, Katherine (2012), Politics and the Art of Commemoration: Memorials to struggle in Latin America and Spain, Londres e Nova Iorque, Routledge.

NADAIS, Inês (2014a), «O passado coletivo jamais será vencido», Público, 13 de Novembro de 2014. -- (2014b), «Um museu para o 25 de Abril - só que vivo», Público, 6 de Junho de 2014.

PITElla, Isadora H. (2013), «COLETIVA Entre Memória e Arquivo», in Arte Capital (http://www. artecapital.net/exposicao-398-coletiva-entre-memoria-e-arquivo).

RICHTER, Gerhard (200o), «Benjamin's Face: Defacing Fascism», in Walter Benjamin and the Corpus of Autobiography, Detroit, Wayne State University Press.

STURKEN, Marita (2008), «Memory, Consumerism, and Media: Reflections on the Emergence of the Field», Memory Studies 1.1 (janeiro), 2008, p. 74 . 